GLOBAL MEDICAL ETHICS

\title{
The bioethical principles and Confucius' moral philosophy
}

\author{
D F-C Tsai
}

J Med Ethics 2005;31:159-163. doi: 10.1136/jme.2002.002113

This paper examines whether the modern bioethical principles of respect for autonomy, beneficence, nonmaleficence, and justice proposed by Beauchamp and Childress are existent in, compatible with, or acceptable to the leading Chinese moral philosophy - the ethics of Confucius. The author concludes that the moral values which the four prima facie principles uphold are expressly identifiable in Confucius' teachings. However, Confucius' emphasis on the filial piety, family values, the "love of gradation", altruism of people, and the "role specified relation oriented ethics" will inevitably influence the "specification" and application of these bioethical principles and hence tend to grant "beneficence" a favourable position that diminishes the respect for individual rights and autonomy. In contrast, the centrality of respect for autonomy and its stance of "first among equals" are more and more stressed in Western liberal viewpoints. Nevertheless, if the Confucian "doctrine of Mean" (chung-yung) and a balanced "two dimensional personhood" approach are properly employed, this will require both theorists and clinicians, who are facing medical ethical dilemmas, of searching to attain due mean out of competing moral principles thus preventing "giving beneficence a priority" or "asserting autonomy must triumph".
Correspondence to: Assistant Professor D F-C Tsai, Department of Social Medicine and Department of Family Medicine, National Taiwan University College of Medicine, Department of Medical Research, National Taiwan University Hospital, No 1, Section 1, Jen-Ai Road, Taipei, 100, Taiwan; fctsai@ha.mc.ntu.edu.tw

Received 10 October 2002 In revised form 26 November 2003 Accepted for publication 1 October 2003

\section{THE FOUR PRINCIPLES APPROACH TO BIOETHICS: CROSS CULTURAL, GLOBAL BIOETHICS}

Immediately after the presentation of the US National Commission's Belmont Report, ${ }^{1}$ which was the first to make three ethical principlesrespect for people, beneficence, and justicecentral to the safeguarding of human subjects in biomedical and behavioural research, Beauchamp and Childress published the Principles of Biomedical Ethics in 1979. Through revision of the five editions, they have developed a principles based, common morality theorynamely, the four principles approach to biomedical ethics, which has played an important role on the stage of contemporary medical ethics in the narrow sense and bioethics in the broad sense for two decades. ${ }^{2}$ This method professes that the principles of respect for autonomy, beneficence, non-maleficence, and justice not only cover most of the bioethics concerns but are also the commonly shared and accepted moral principles no matter what one's ethical, political, religious, or cultural stances are. ${ }^{3}$ Therefore they should be plausibly applied internationally and across cultures.

Nevertheless, does a universal morality exist? Can foundations of global bioethics be found? When a bioethics method has been developed based on certain Western mentality, can it be used or transferred to other societies whose ethos, religions, social and cultural backgrounds, as well as the characteristics, perceptions, and nature of bioethical problems, are entirely different? More specifically, can these prominent Western bioethical principles proposed by Beauchamp and Childress be applied transculturally to Chinese and even East Asian societies whose traditional ethos was essentially based on Confucian ethics?

\section{ANCIENT CHINESE MEDICAL ETHICS AND CONFUCIUS' MORAL PHILOSOPHY}

Confucius is one of the most influential thinkers of Eastern philosophy and a representative of Eastern culture. Confucius, together with Socrates, Gautama Buddha, and Jesus Christ were regarded by Jaspers ${ }^{4}$ as the four paradigmatic individuals, owing to their extended influence through two millennia and their extraordinary importance for all philosophy. Ancient Chinese medical ethics was established on the foundation of Confucian ethics whose central theme is humaneness (jen) and whose distinctive features are deontology and virtue ethics. The traditional ethical standards require that Chinese physicians reach the moral standard of an ideal Confucian person or chun-tzu, the superior man. ${ }^{5}$ It will be interesting to compare the four principles approach to bioethics with the Confucius' ethics and investigate the intercultural applicability of the four principles method.

The key concepts of Confucius' moral philosophy can be concisely delineated as follows:

- The merging of self cultivation and social-political reform. Confucius believed that political order must be established on social order, and social order must come from individual cultivation. Therefore he said, "From the Son of Heaven down to the mass of the people, the cultivation of the self is the foundation of everything besides." "Their hearts being rectified, their persons were cultivated. Their persons being cultivated, their families were regulated. Their families being regulated, their States were rightly governed. Their States being rightly governed, the whole kingdom was made tranquil and happy." ${ }^{\prime \prime}$ 
- The pursuit of dao. Dao generally means road or path, method, way, doctrine, the truth, or moral teachings. It has been interpreted as the supreme metaphysical force that exists everywhere in everything and dominates the exercise and function of all things in the universe, ${ }^{7}$ as well as the universal moral order and the ideal status of moral achievement for man to define, pursue, and accomplish. ${ }^{8}$ According to Schwartz, it is "an all encompassing state of affairs embracing the 'outer' socio-political order and the 'inner' moral life of the individual".. Humankind should seek the comprehension and pursuit of life in accordance with dao. Therefore Confucius said, "What Heaven imparts to man is called human nature. To follow our nature is called the dao. Cultivating the dao is called education". ${ }^{10}$ "If a man in the morning hears the dao; he may die in the evening without regret!"11 Mencius explained, "Humanity (jen) is the distinguishing characteristic of man. When embodied in man's conduct, it is the dao."10

- The ethical system of jen (humaneness)-yi (righteousness)- $l i$ (rules of propriety). Confucius' teachings of jen, yi, and li comprise the most fundamental thought and principles in Confucius' ethics. Jen has been translated as love, benevolence, humanity, human heartedness, virtue, perfect virtue, true manhood, and humaneness; it also signifies the ideal relationship between people. $Y i$ generally means righteousness, appropriateness, obligation, and justice, and is "the principle of setting things right and proper".$^{10} \mathrm{Li}$ indicates ceremony, rites, decorum, courtesy, etiquette, rules of propriety, and at first represents the ceremonial order, but in the full sense connotes the sociopolitical order. ${ }^{9}$ Jen (humaneness) and $y i$ (righteousness) could be said to be the inner core of morality that motivates and guides man to pursue the dao, and $l i$ (rules of propriety) could be described as the outer form and standard of morality that is concrete for man to abide by in the context of human society.

- The moral ideal of chun-tze (the superior man or gentlemen). Chun-tze is the man of high moral achievement who constantly tries to improve and cultivate himself to achieve various stages of perfection. ${ }^{8}$ The moral character of Chun-tze demonstrates both the qualities of "an autonomous person", which includes self activation, self determination, self reliance, and self cultivation, and "a relational person" who is committed to other-regarding morality and altruism. ${ }^{12}$ The ultimate concern and self realisation of a Confucian ideal person consists in giving security and peace to people, yet in order to achieve this goal one must become a chun-tze first, which requires incessant moral self cultivation. ${ }^{10}$

- The wu-lun (five basic human relationships). Confucius stresses family values and filial piety through articulating the five basic human relationships "which govern the relationship between ruler and minister, between father and son, between husband and wife, between elder and younger brothers, and those in the intercourse between friends". ${ }^{10}$ The $w u$-lun gave form to Chinese society and social institutions from government down to interpersonal transactions and has far reaching influence on the East Asian, Confucian ethics based cultures. ${ }^{8}$ Confucius believes good family breeding naturally leads to good social intercourse. Therefore: "A superior man is devoted to the root. When the root is firmly established, the moral law (dao) will grow. Filial piety (shaw) and brotherly respect (ti) are the root of humanity (jen)." 10

In addition to these fundamental concepts, it is important to recognise that Confucius' ethics were developed in an epoch of chaos aiming at restoring social order and promoting general welfare through everyone's moral self cultivation and fulfilling one's own responsibilities. Therefore, apart from the strong deontological and virtue ethics characteristics, Confucius inevitably adopted a consequentialist approach in many sociopolitical contexts in order to pursue public interest. Confucius' morality, with its cardinal claims of "cultivating oneself so as to bring peace and prosperity for people" ${ }^{\prime 10}$ and "sagely within and kingly without", professes a sense of solidarity and selflessness that communitarians advocate. It is then necessary to resort to the "principle of utility" because calculating what might contribute most to the public interest becomes a fundamental moral value. Based on this basic understanding of Confucian moral values, we now examine the four bioethical principles and their relevance to Confucian ethics.

\section{RESPECT FOR AUTONOMY}

As Confucius' ethics is compared to the Western theories of the principle of respect for autonomy, one may find that among the many virtues which Confucius requires of a chuntze, the morally ideal person, the virtues of "hsin" (faithfulness, truthfulness), "gong" (respectfulness), and "jing" (reverence) are virtues which correspond to the principle of respect for autonomy and its derivative rules of veracity and fidelity. Confucius' teaching emphasises the importance of "free will" and "self legislation" in one's pursuit of humaneness (jen), and questions the efficacy of using law and punishment in rectifying people's conduct. He said: "Lead the people with governmental measures and regulate them by law and punishment, and they will avoid wrongdoing but will have no sense of honour and shame. Lead them with virtue and regulate them by the rules of propriety (li), and they will have a sense of shame and, moreover, set themselves right." ${ }^{10}$ Confucius' version of the golden rule, the principle of jen (humaneness), connotes the love and respect one should have towards fellow people. On the other hand, Confucius' concepts of chun-tze (the superior man), which illustrates the characteristics of self activation, self cultivation, self reflection, self reliance, and moral authenticity, ${ }^{12}$ not only fully expresses the qualities of an autonomous person but also displays the value and dignity of being an individual: "to be an end of oneself, not a means of others". In effect, the aim of Confucius' moral education is for the cultivating of an autonomous person.

Nevertheless, further investigation into the conceptions concerning "persons" reveals interesting but important differences. I have argued in another paper that the Western conceptions of personhood-to which modern bioethicists often refer-and on which the principle of respect for autonomy relies, basically emphasise the standards of rationality and self consciousness of the moral agent who is hence entitled to liberty and the right to choose for himself. The Confucian personhood might embrace such ideas with little difficulty but additionally advocates a strong relational perspective, the "horizontal dimension" of being persons. Specifically, personhood in the Confucian sense comprises not merely the moral faculties of rationality and self consciousness one is born with, but a moral accomplishment for one to achieve in a cultural-historical tradition stressing the individual's relationships with and altruistic responsibility towards others. "When a person exercises autonomy, he is not choosing in a context-free, conceptual vacuum manner but considers himself a person-in-relation with many roles to play and responsibilities to take in accordance with different relationships. A person cannot become fully human without fulfilling his role-specified relation-oriented responsibilities; the Confucius personhood is to be realised through interpersonal transactions in human society." ${ }^{12}$ 


\section{BENEFICENCE AND NON-MALEFICENCE}

The principles of beneficence and non-maleficence are here considered as a conjoined moral obligation to be compared with Confucius' principle of jen (humaneness) and concept of chun-tze (the superior man). Confucius' principle of jen purports "love" and the "golden rule". It is also expounded through the idea of chung (conscientiousness): "establish one's own character" and shu (reciprocity): "also establish the character of others" ${ }^{\prime 10}$ This echoes a reciprocity based justification for beneficence (which includes non-maleficence): "I received benefits from others therefore in return I promoted their welfare." ${ }^{\prime 13}$ Confucius professed his principle of jen in both negative form: "not to do to others what you do not want them to do to you", ${ }^{11}$ and positive form: "wishing to establish one's own character, seeks also to establish others; wishing to be prominent oneself, also helps other to be prominent". ${ }^{11}$ These moral doctrines display a reciprocity based moral justification and expressly and respectively corresponded to the principle of non-maleficence and the principle of beneficence. Besides, Confucius made the "negative form" of the golden rule, shu (reciprocity), the minimal standard for moral agents, "the one word to serve as guiding principle for conduct throughout life", ${ }^{11}$ because non-maleficence is a perfect duty that everyone should not transgress, while beneficence is a moral ideal to which a chun-tze is committed.

However, in Confucius' theory when jen pronounces love, it has as its origin biological bond and starts from the intimate affection and respect learnt and shared in the family. This love then endeavours to extend towards other people, therefore it is neither "partial" nor "universal" but "gradational". The natural gradational pattern of love such as a mother's love and care for her own children before looking after others' children is of the most unexceptional human nature, a "partiality" that is "universally" valid. In considering doing good or being beneficent to others without ignoring the fact that everyone has but limited resources, paying "attention to the scope" and adapting a pragmatic, progressive, and stepwise approach based on "gradational love" is sensible. Confucius' formula professes "Treat with respect the elders in my family, and then extend that respect to include the elders in other families. Treat with tenderness the young in my own family, and then extend that tenderness to include the young in other families." ${ }^{11}$ This is to avoid aiming too high for the ethical idealism of universal love of "caring for strangers as dearly as we care for our parents", but eventually ending up "treating our dearly beloved as apathetically as we treat passers-by". ${ }^{14}$ After all, the Confucian utopia is the realisation of a universal philanthropy starting from intimate love and respect shared within family then progressing step by step toward clan, community, country, and the world. The approach of gradational love in effect gives the principle of beneficence a sensible, ethical, and practical strategy for realising it.

Furthermore, the Confucian viewpoints of beneficence and non-maleficence can be interpreted by his moral ideal of people: the concepts of chun-tze. Chun-tze, as a relational being, through his rational self consciousness and reflection, embraced a deep moral concern and altruistic commitment towards others and society. He values his relatedness, mutuality, and communion with others more than his own separateness, individuality, and distinctiveness. ${ }^{12}$ As Hansen has insightfully pointed out, "A Western theory might portray the world as made up of particulars, whereas Chinese philosophy regarded objects as parts carved out of a large, basic whole."15 In the Confucian view, the "selfhood" is the centre of relations but its boundary with others is not always clear. The realm of selfhood may include family, community, country, and the world; moreover, the self seeks in his lifetime to be in unity with the dao (the universal moral order) thus realises his true selfhood. ${ }^{12}$ A chun-tze's missions in summation, "cultivating oneself so as to give all people security and peace", should therefore be understood not only as a process of broadening oneself to embody an ever expanding circle of human relatedness, but also a course of deepening in self transformation through genuine communion with others. ${ }^{14}$

It becomes clear that, based on the unique sense of Confucian selfhood and the relational personhood, to describe the principles of beneficence and non-maleficence as an external moral duty added unto one or a utilitarian endeavour to create the best utility for all would be imprecise. Altruism is intrinsic, immanent, and constituent to what counts as a Confucian ideal person. It is through altruism one realises one's true manhood and achieves humanity (jen).

\section{JUSTICE}

Justice in Confucius' ethics can be interpreted by the principle of $y i$ (meaning righteousness, appropriateness, and justice). When yi purports "righteousness", it refers to the "substance" or "standard" of morality signifying "the right things to do and doing the things right". Confucius' theory of "rectification of names", which denotes that everyone should rightly fulfil one's role attached responsibilities and thus live up to their "names", ${ }^{10}$ is similar to Socrates' idea of state of justice: every class does its own job and minds its own business. ${ }^{16}$ Confucius' concept of the "dao of righteousness" emphasises a person's insistence upon "the righteous way" (morality) should never be compromised under any circumstances-poor or rich, honoured or humble, prosperous or adverse. ${ }^{10}$

When yi indicates "appropriateness", it asserts the art of applying moral rules with flexibility (chuan), ${ }^{10}$ searching to attain due Mean (chung-yung) out of competing or contradictory moral values, and respecting and abiding by the good social norms ( $l i$, the rules of propriety). Merely holding fast to moral rules without considering their appropriate implications could make moral life a burden or even a disaster, because moral rules frequently conflict with each other and exceptional circumstances are simply unavoidable. Confucius' notions of chuan (flexibility) and chung-yung (the doctrine of the Mean), when compared to Beauchamp and Childress' theories of "specifying" moral principles according to the particular contexts, "balancing and overriding" the conflicting moral principles, ${ }^{2}$ and using "reflective equilibrium $^{\prime 2}$ to reach a coherence between moral theories and practices, display a great resemblance and deserve further investigation.

When yi denotes "justice" in Confucius' ethics, it is concerned with regulating the selfish desires and limiting the endless pursuit of self profit. It represents the judging criterion when one is in the face of "gaining profit" - to take when it is just to do so, ${ }^{10}$ therefore it implies a fair acquisition and distribution of resources. When there are conflicts between public interest and self interest, individual benefits and moral principles, $y i$ as justice maintains the prioritisation of: first, justice; second, profit (first, the public interest; second, the self interest) according to Confucius.

After examining the three meanings of $y i$, I believe that there is no definite material principle of justice in Confucius' ethics. When yi indicates righteousness and appropriateness, it advocates both the primacy of morality and the importance of applying moral rules with flexibility. When yi signifies justice, it purports vaguely the ideas of "desert" therefore referring to distributive justice. So it is necessary to examine from a broader basis what values in Confucius' ethics might influence the specification and application of the principle of justice. 
I propose that the "five basic human relationships (wulun)" in Confucius' theory were constructed in hierarchical patterns. ${ }^{17}$ The relative positions between father and son, husband and wife, old and young, and ruler and minister were graded as the higher, authoritative side and the lower, subordinate side; they were obviously unequal. This might have its cultural, historical background with the aim of restoring and maintaining social order. Yet if mutual respect and each party's fulfilling its role specified responsibility can not be established, the unequal status coming from the hierarchy might cause the rights and autonomy of the lower, subordinate sides to be coerced or exploited by the higher, authoritative sides therefore undermines justice.

On the other hand, the "gradational love" and the "role specified, relation oriented ethics" require the exhibition of unequal love and respect towards different subjects according to the psychological distance, blood ties, or relationships, which could be reckoned as an application of "unequals should be treated unequally". However, its misuse might lead to people treating their loved ones preferentially with public resources, being partial in distributing communal or collective assets to benefit their families or acquaintances regardless of the fair procedures, and consequently resulting in clanism and nepotism. Using "relation" or "renqing" (human affection or relation) to influence the communal resources allocation could also be problematic as it might lead to coercion, corruption, or partiality, thus jeopardising social justice. Therefore, the gradational love and relational based approach to justice should be modulated by the principle of $y i$, and its application should be limited within a non-public scope, so that justice will not be impaired by selfish reasons.

Justice in a sense is about adjudicating competing legitimate claims or conflicting moral values. However, filial piety seemed to have a special place-even a priority-in Confucius' ethics when it clashed with other moral duties or principles. Two stories from Confucian Classics reveal that legal justice or retributive justice had no absolute power in Confucius' and Mencius' ethical theories that social justice might sometimes have to be compromised with or even be overruled by filial piety and family values. Firstly, it is recorded in the Confucian Analects: The Duke of She told Confucius, "In my country there is an upright man named Kung. When his father stole a sheep, he bore witness against him". Confucius said, "The upright men in my community are different from this. The father conceals the misconduct of the son and the son conceals the misconduct of the father. Uprightness is to be found in this." ${ }^{10}$ Secondly, it is described in Mencius: Tao Ying asked, saying, "Shun being sovereign, and Kao-yao chief minister of justice, if Ku-sau [Shun's father] had murdered a man, what would have been done in the case?" Mencius said, "Kao-yao would simply have apprehended him". "But would not Shun have forbidden such a thing?" "Indeed, how could Shun have forbidden it? Kao-yao had received the law from a proper source." "In that case what would Shun have done?" "Shun would have regarded abandoning the kingdom as throwing away a wornout sandal. He would privately have taken his father on his back, and retired into concealment, living somewhere along the seacoast. There he would have been all his life, cheerful and happy, forgetting the kingdom." ${ }^{18}$

Confucius' ethics basically asserts that filial piety and fraternal love are the roots of humaneness, the foundation and origin of human morality; all social goods are extensions of family ethics. ${ }^{11}$ Therefore, although Confucius professes the non-negotiability of holding fast to justice, when filial piety and justice conflict, he is reluctant to harm the roots in order to preserve the branches. Trying both to comply with filial piety to one's parents and to discharge one's various moral duties toward others at the same time often incurs tension or ethical dilemmas for which no easy solutions are available. In Confucius' ethics as well as in a traditional Chinese society, reconciling justice in preserving the virtue of filial piety is a peculiar moral value that should not be neglected and should be examined.

\section{CONCEPT, CONCEPTIONS, AND APPLICATION}

From the foregoing review, the conclusions of this paper are clear. The concepts of respect for autonomy, beneficence, non-maleficence, and justice and the moral values of these four prima facie principles have been expressly identified in Confucius' ethics. It would be plausible to say that Confucius' moral philosophy, professing jen (humaneness), yi (righteousness, appropriateness, justice), li (rule of propriety), and chun-tze (the self cultivated, autonomous man committed to altruism), is compatible with and even perhaps asserts the bioethical principles of respect for autonomy, beneficence, non-maleficence, and justice. In other words, what Beauchamp and Childress have advanced as four prima facie moral obligations adopted from the "considered judgements" of "common morality" have literally been existent and discernible in Confucius' ethics for the past 2500 years. In this paper I have verified their presentations in Confucius' ethics, and reconstructed and interpreted Confucius' ethics in the light of the Western theories of the four bioethical principles. To say that people from the Confucian ethics based societies will find little difficulty in committing themselves to these four prima facie moral obligations is basically sustainable through this paper's examination.

Although Confucius' ethics share the same "concepts" of the four principles, their "conceptions" of the four principles are different in certain aspects. By Lindey's definition "a conception is a particular interpretation or analysis of a concept" and "an adequate conception must fall within the scope of the basic concept". ${ }^{19}$ Taking Herodotus' famous story of Darius, the ancient Persian king, who found that the Callatians (an Indian tribe) customarily ate the bodies of their dead fathers, while Greeks practised cremation and burned the bodies of their fathers when they died. Darius then summoned some Callatians and some Greeks and asked them to practice each other's customs-the Greeks to eat their dead fathers and the Callatians to burn theirs. Both of them were horrified by the idea and replied that not at any price could Darius make them do such a dreadful thing. ${ }^{20}$ Cultural relativists might use such a story to illustrate that different cultures have different moral codes and claimed "custom is king", but it appears perfectly clear to the author that although the rites or social practices-the conceptions of how to treat dead fathers with respect-might differ greatly, the concept of respecting the deceased fathers remains the same. Burning a national flag was considered an insult to the state and a crime forbidden in some countries years ago, but it was later interpreted as an expression of "freedom of speech" which is a protected right by the Constitution of the United State. Therefore, one "concept" may have many different "conceptions" as it is interpreted and modulated in various contexts; so similarly with the concepts of the four prima facie moral principles which may have many diverse but adequate conceptions.

Beauchamp and Childress' principles oriented framework has defined the four principles to be prima facie binding yet without a priori ranking. It must be through "specification", "balancing and overriding" of the principles that one arrives at coherent and justifiable answers to ethical dilemmas when the principles come into conflict. However, it is conceivable that cultural factors or social practices could hugely influence these processes. In other words, the conceptions of a certain concept, more than the concept itself, play the cardinal roles 
in influencing the actual application, whereas a concept without specification is merely an abstract guidance.

\section{CONCLUDING REMARKS}

I have argued that the two basic elements of a Confucian "person" encapsulated in the moral ideal of chun-tze are crucial in understanding the "conceptions" of respect for autonomy, beneficence, non-maleficence, and justice in both Confucius' ethics and their application in a Confucian culture based society. Firstly, chun-tze is an "autonomous person" who is rational, self conscious, and commits himself to moral self cultivation. Secondly, chun-tze is a "relational person" who appreciates filial piety, gradational love, and role specified, relation oriented ethics, and realises altruism in interpersonal transactions. ${ }^{12}$ This two dimensional concern, which includes the vertical dimension (the autonomous, self cultivating one) and the horizontal dimension (the relational, altruistic one), runs through the construction of a chun-tze's moral life, and influences how these four principles will be put into practice. Moreover, taking into account many traditional cultural characterisations and existing social practices, "relational personhood" clearly might have a strong influence in a Chinese culture based context, and thus gives the "conceptions" or interpretation of the four principles a tendency towards "relational orientation".

Accordingly, the Confucian "conceptions" of the four prima facie principles can plausibly echo and buttress the communitarian and feminist theses which endorse the common good, duty to others and society, the person-inrelation, and the ethics of care. It also tends to grant beneficence a favourable position that at the same time might diminish the respect for individual rights and autonomy when moral principles clash. This is different from the Western liberal viewpoints, which have more and more argued for the centrality, priority, and the stance of "first among equals" of the principle of respect for autonomy, that constitutes an interesting contrast. As Callahan points out: "Autonomy is, then de facto given a place of honour because the thrust of individualism, whether from the egalitarian left or the market oriented right, is to give people maximum liberty in devising their own lives and values."21 Nevertheless, if the Confucian "doctrine of Mean (chung-yung) and a balanced "two dimensional personhood" approach are properly employed, this would require both theorists and clinicians, who are facing medical ethical dilemmas, to attain due mean out of competing or contradictory moral principles, thus preventing either "giving beneficence a priority" or "asserting autonomy must triumph".

Although bioethical principles and methods have been developed for action guidance and problem solving, tough moral decisions in medical practice, that may have not simple or direct solutions, still challenge physicians, patients, and their families every day. This reminds us the complexity of medical ethical decisions and the risks healthcare professionals undertake in confronting them. Further effort from moral philosophers in articulating and constructing comprehensive and applicable theoretical frameworks for bioethics discourse is still much needed. In this process, philosophical heritage from non-Western, non-English speaking cultures might have an important contribution to make. Confucius' moral philosophy of antiquity provides unique ideas and insightful understanding of person, humanity, interpersonal relationships, and moral community, which under careful examination and critical transformation can become useful resources for further deliberation. On the other hand, the four modern bioethical principles, compared with and explicated through Confucius' moral teachings, have become compatible with and hence applicable in the Confucian cultured based, East Asian societies. Modern medical professionalism has adopted these principles and reasserted that medicine is a moral career, not a profit making business. ${ }^{22}$ This chimes with the ancient Confucian medical morality, which requires doctors of "the heart of humaneness and the arts of humaneness" and regards practicing medicine equal to realising humaneness.

\section{ACKNOWLEDGEMENTS}

The author would like to thank Professor John Harris, Professor Raanan Gillon, and Professor Søren Holm for their inspiring comments on the earlier drafts of this paper.

\section{REFERENCES}

1 National commission for the protection of human subject of biomedical and behavioral research, The Belmont report: ethical principles and guidelines for the protection of human subjects of research. DHEW Publication No 78-00 (OS). Washington, DC: Department of Health, Education, and Welfare Publication, 1978

2 Beauchamp TL, Childress JF. Principles of biomedical ethics, 5th edition. New York: Oxford University Press, 2001.

3 Gillon R. Medical ethics: four principles plus attention to scope. BMJ 1994;309:184-8. Also see Gillon R. Ethics needs principles four can encompass the rest-and respect for autonomy should be "first among equals". J Med Ethics 2003;29:307-12.

4 Jaspers K. The great philosophers. London: Rupert Hart-Davis, 1962:6.

5 Tsai DFC. Ancient Chinese medical ethics and the four principles of biomedical ethics. J Med Ethics 1999;25:315-21.

6 Legge J, [translated by]. The Great Learning, In:The Chinese classics Vol. 1. Taipei: SMC Publishing Inc, 1991:359. [Translation modified by the author]. 7 Legge J, [translated by]. The I Ching. New York: Dover Publications, 1963:355.

8 Lin YT. From pagan to Christian. New York: The World Publishing Company, 1959:71.

9 Schwartz BI. The world of thought in ancient China. Cambridge, MA: The Belknap Press of Harvard University Press, 1985:67-8.

10 Chan WT. A source book in Chinese philosophy. New Jersey: Princeton University Press, 1969, 20, 22, 26, 27, 40, 41, 43, 45, 81, 98, 104, 105 $217,280,337$. [Translation modified by the author].

11 Legge J, translated by. Confucian Analects, In:The Chinese classics Vol.I. Taipei: SMC Publishing Inc, 1991, 20, 31, 39, 61, 168, 301. [Translation modified the author].

12 Tsai DFC. How should doctors approach patients? A Confucian reflection on personhood. J Med Ethics 2001;27:44-50.

13 Hume D. Of suicide. In: Miller E, eds. Essays, moral, political, and literary. Indianapolis, IN: Liberty Classics, 1985:577-89.

14 Tu WM. Confucian thought: selfhood as creative transformation. New York: State University of New York Press, 1985:123-4.

15 Hansen $\mathrm{C}$. Chinese philosophy and human rights: an application of comparative ethics. In: Becker GK, eds. Ethics in business and societyChinese and Western perspectives. Hong Kong: Springer, 1997:108.

16 Plato. The Republic, Translated by Lee D. London: Penguin Books, 1987, 206, $433 c-d$.

17 Bond MH, Hwang KK, The social psychology of Chinese people, In: Bond MH, eds. The psychology of Chinese people. New York: Oxford University Press, 1986:215-6.

18 Legge J, [translated by]. The work of Mencius, In: The Chinese classics Vol.II. Taipei: SMC Publishing Inc, 1991:469-70.

19 Lindley R. Autonomy. London: Macmillan Education Ltd, 1986:3.

20 Herodotus, Custom is King, In: Ladd J, eds. Ethical relativism. Lanhan, MD: University Press of America Inc, 1985:12.

21 Callahan D. Principlism and communitarianism. J Med Ethics 2003;29:275-80.

22 ABIM Foundation, ACP-ASIM Foundation, European Federation of Internal Medicine: Medical Professionalism in the New Millennium: A Physician charter. Ann Intern Med 2002;136:243-6. 